\title{
Apetições rítmicas atadas em feixes: Whitehead e o campo da arte
}

Vinícius Portella Castro ${ }^{1}$

RESUMO: Este trabalho tenta apresentar o conceito de "apetição" (appetition) de Alfred North Whitehead, e dimensioná-lo para a delimitação de uma problemática ecológica do campo artístico. Sem me orientar pelas formulações explícitas de Whitehead a respeito da arte, procuro oferecer um esboço de como aspectos da sua filosofia poderiam ajudar a formular uma filosofia da arte radicalmente distinta dos moldes e circuitos da estética moderna. Para tanto, apresento o conceito de "apetição", retomado de Leibniz e modificado por Whitehead em "Process and Reality", e tento explicar de que modo a potência desse conceito poderia oferecer alternativas para alguns limites da noção de 'forma' na arte. Também tento relacionar a 'apetição' com a criatividade em Whitehead e com a dimensão rítmica de sua concreção.

PALAVRAS-CHAVE: Alfred North Whitehead; Gottfried Leibniz; apetição; ritmo

ABSTRACT: This paper attempts to present Alfred North Whitehead's concept of 'appetition', and size it up to the delimitation of an ecological problematic of the artistic field. Without following too closely Whitehead's explicit formulations on art, I try to offer a sketch of how some aspects of his philosophy could help to create a philosophy of art that is radically distinct from the molds and circuits of modern aesthetics. With this goal, I present the concept of 'appetition', that Whitehead takes from Leibniz and expands, and I try to explain how this concept's potency could offer interesting alternatives to the limits of the concept of 'form' in art. I also try to relate appetition to creativity in Whitehead and with the rhythmic dimensions of its concretion.

KEYWORDS: Alfred North Whitehead; Gottfried Leibniz; appetition; rhythm

"Apetição é matéria imediata de fato incluindo em si mesma um princípio de inquietude, envolvendo realização do que não é e pode ser"” A.N.

Whitehead

"A criatividade é o derradeiro por trás de todas as formas, inexplicável por formas, e condicionada por suas criaturas.” A.N. Whitehead

"O desejo do Homem sendo infinito a possessão é infinita e ele mesmo infinito"

William Blake ${ }^{3}$

\section{Introdução - Whitehead e a arte}

Este trabalho tentará apresentar o conceito Whiteheadiano de apetição para, em seguida, modificá-lo e estendê-lo para o estabelecimento de uma problemática ecologica do campo artístico orientada a ritmos e meios materiais. O ponto de vista teórico de onde parto é o de uma ecologia

\footnotetext{
${ }^{1}$ Doutor em literatura comparada (UERJ)

${ }^{2}$ No original: "Appetition is immediate matter of fact including in itself a principle of unrest, involving realization of what is not and may be."

${ }^{3}$ No original: "The desire of Man being Infinite the possession is Infinite \& himself Infinite."
} 
materialista dos meios ${ }^{4}$ de comunicação, baseada em autores como Gregory Bateson, Félix Guattari, Isabelle Stengers e Gilbert Simondon

Apetição não é exatamente um dos conceitos centrais de Processo e Realidade (não chega ali na classe privilegiada dos objetos eternos, preensões, entidades atuais ou os nexos), mas Whitehead lhe dá uma expansividade de aplicação que pode muito bem, acredito, servir para alguns dos anseios da teorização atual da literatura e da arte em geral. Em especial, creio que as "apetições" podem apresentar soluções interessantes para os limites atuais do conceito de forma.

A apetição não ter um papel central no edifício alto e intrincado da filosofia de Whitehead não quer dizer que à ideia não é dada uma carga significativa. Afinal, ele propõe que a origem da vida se daria devido à "novidade de apetição" (novelty of appetition), que ele equivale com "novidade conceitual" (conceptual novelty). Para Whitehead, na apetição pela diferença que demonstra um ser vivo simples com sede, no vislumbramento (envisagement) que o acomete na sua busca por satisfação subjetiva, já encontraríamos o germe da imaginação livre.

Essa novidade conceitual da vida para Whitehead é aquilo que a distingue da informação dada (data) que ela herdou. Algo vivo é exatamente algo que atinge um patamar de resolução que não estava disponível antes naquele conjunto de informação herdada (WHITEHEAD, 1985, p.104), ou naquela rota tradicional de ocasiões. Acontece uma produção de novidade nessa mudança de fase, ainda que não se trate de uma descontinuidade absoluta com o que vem antes.

Embora não seja minha pretensão apresentar um panorama exaustivo da filosofia de Whitehead, durante o percurso vamos também acionar alguns dos elementos estruturais mais importantes do seu pensamento, não apenas para poder explicar o conceito de apetição de maneira mais extensa e precisa, mas também para dimensionar melhor a potência que pode guardar o pensamento de Whitehead para a arte em geral.

Em especial, nos servirá de orientação ao longo do trabalho a compreensão de Whitehead de uma estrita e extensa solidariedade cósmica, o fato de que qualquer evento singular preende (de maneira positiva ou negativa) o universo inteiro.

Ou, como diz Whitehead em Processo e Realidade: “Cada tarefa de criação é um esforço social empregando o universo inteiro.”(1985, p.) Whitehead não foi o primeiro a dizer isso,claro. Leibniz, na sua Monadologia, já dizia que a inter-comunicação das coisas se estende a qualquer distância e cada corpo sentiria o efeito de tudo que se dá no universo ${ }^{5}$.

\footnotetext{
4 'meio' nos sentidos aqui simultâneos de suporte, instrumento e ambiente.

5 (ainda que a alma apenas consiga ler o que está distinto nela, e não consiga desdobrar tudo que está dobrada em si, sua complexidade sendo infinita).
} 
Mas Whitehead integra essa ideia na sua filosofia com uma integralidade imaginativa e uma exaustividade sistêmica que ela parece assumir outras feições (influenciado, claro, pelos incrementos de resolução na ideia que se tem da matéria e da interação sub-atômica no início do século XX)

Como podemos transpor uma compreensão cósmica dessas para a dimensão da arte? Se já é difícil empreender o esforço imaginativo de depreender de um objeto de arte recortado a sua dimensão social, se já se demonstra quase impossível aumentar essa extensão relacional para incluir com rigor conceitual dimensões sistêmicas mais amplas, ecológicas, como é que podemos levar a sério uma demanda imaginativa tão exaustiva?

Então qualquer episódio trivial de seriado meia-boba, qualquer canção genérica que parece produzida no automático, o produto mais inconsequente e desinteressante de uma indústria de entretenimento envolve e desdobra a concreção coletiva de todo o universo. Dependendo do trajeto, esse trem de pensamento pode acabar num resultado mais deprimente do que encorajador. Ou, ainda, esse sentimento desmedido de conectividade pode constranger e inibir o artista mais tímido, de repente preocupado com a responsabilidade de envolver o universo todo num gesto de sua responsabilidade. O próprio Whitehead torna bastante claro que existem gradientes de relevância, é claro que aglomerados de galáxias distantes da Via Láctea só estão envolvidos na "Comédia Humana" ou na discografia do "É o Tchan" de maneira bastante indireta e distante.

Apesar das gracinhas, a minha tentativa aqui será de levar as ideias ultrajantes de Whitehead a sério. Além disso, também vamos considerar a centralidade que o conceito de criatividade detém na filosofia de Whitehead, e de que maneira essa centralidade poderia desembocar em uma filosofia materialista da arte radicalmente diferente daquela instaurada desde o romantismo, com seus circuitos de autoria e invenção individualista (onde os artistas originais colonizam território novo do imaginário para torná-lo sua propriedade).

Talvez o primeiro efeito significativo que Whitehead teve na filosofia da arte foi por via da obra de Susanne Langer, que não o citava diretamente mas que foi sua aluna, e parecia seguir linhas de investigação e formulação um tanto Whiteheadianas. Mais recentemente (2009), tivemos o esforço de Steven Shaviro de apresentar algo como uma estética Whiteheadiana no livro "No Criteria". Nesse livro, Shaviro se põe a imaginar o que seria o pensamento do século XX se "Processo e Realidade" tivesse cumprido o papel epocal do tomo de Heidegger, "O Ser e o Tempo". A proposta sem dúvida é interessante, mas além de me incomodar com algumas das escolhas conceituais de Shaviro (como a de tratar "afeto" e "sentimento" como intercambiáveis), não vamos repetir os seus passos por uma diferença crucial com a minha estratégia aqui. Enquanto Shaviro situa o seu debate com uma leitura 
Whiteheadiana da estética de Kant, a perspectiva que orienta a nossa produção do campo problemático da arte está mais próxima da antropologia da arte e da teoria dos meios do que da Terceira Crítica.

Whitehead nunca escreveu uma obra especificamente dedicada à estética ou à arte. No entanto, é possível dizer que a dimensão estética detém uma relevância considerável na sua filosofia, o que se evidencia não só pelo apelo que sua generalização metafísica faz à imediatidão emocional da experiência concreta como pelas menções específicas à arte que ele faz ao longo do "Processo \& Realidade" e nos capítulos finais de "Adventures of Ideas".

Nessas menções, nada sistemáticas mas bem enfáticas, Whitehead parece apresentar, por um lado, uma compreensão bastante tradicional da arte, dizendo que extraímos satisfação do reconhecimento de padrões harmônicos e da re-encenação de impulsos que já foram necessidades fisiológicas (WHITEHEAD, 1967, p.272). Com a arte, construímos um domínio de liberdade onde podemos encenar a transfiguração fícticia dos limites reais do reino de necessidade. Por outro lado, Whitehead também encontra na arte uma espécie de hipertrofia mórbida e mesmo de reação psicopática da espécie às tensões de sua existência.

Essas menções, no entanto, não servirão a esse artigo como orientação principal. Por mais que a estética explícita de Whitehead mereça atenção por sua conta, parece-me mais interessante explorar a potência do seu vocabulário conceitual para explorar problemáticas mais amplas, ecológicas e sistêmicas, do campo artístico. Sem desprezar o interesse especulativo da importância que Whitehead dá para a beleza em Adventures of Ideas, por exemplo, acredito que o próprio autor não antecipasse como o resto da sua filosofia poderia transformar radicalmente a compreensão que temos da arte enquanto processo rítmico coletivo de co-modulação expressiva.

Afinal, que espécie de filosofia da arte pode ser produzida por uma filosofia que generaliza a experiência para todo o universo? Para Whitehead, a consciência é um caso especial da experiência e da subjetividade A consciência pressupõe experiência, mas a experiência e a subjetividade não pressupõem consciência. Uma entidade atual pode ou não estar consciente de parte da sua existência, mas a sua experiência sempre se dá por meio de sua constitução formal completa (WHITEHEAD, 1985, p.53).

Isso não é um panpsiquismo, mas é algo talvez ainda mais estranho. Não é tudo pensa, mas sim tudo experimenta. Tudo sente. É importante lembrar, claro, que o sentido de palavras familiares se vê quase sempre transfigurado em Whitehead. A ideia de experiencia precisa ser esgarçada até os seus limites para que possamos compreender como Whitehead pode estendê-la de maneira tão ilimitada. 
Da mesma forma, cabe também perguntar do que seria capaz uma arte que compreendesse integralmente a proposta de Whitehead de tomar a ideia de "energia" como intensidade emocional quantitativa, ou seja, uma arte que comprendesse qualquer vetor informacional como um modo determinado de transmissão de intensidade emocional.

Dentro desse estranho campo especulativo de Whitehead, concreto e ideal, antiquado e radical, a arte pode se apresentar como modulação do vasto espectro experimental do cosmos, propagação e intensificação de energia (ou seja, emoção).

Continue sintonizado.

\section{O que é uma apetição?}

Whitehead refere o conceito de apetição a Leibniz e sua Monadologia. Lá, a apetição é uma tendencia interna de mudança, de ir de uma percepção à outra ${ }^{6}$. Em Leibniz, como em Whitehead, a apetição parece constituir uma tentativa de formular uma teoria do desejo a partir de uma noção mais geral de ímpeto formal ou de tendência estruturante. O exemplo que Leibniz dá, retomado por Whitehead, é a sede. O autor não explica qual é a diferença da apetição de Leibniz em relação a sua.

Uma apetição é, nos termos de Whitehead, ao mesmo tempo a valorização conceitual de um sentimento físico combinado com o ímpeto em direção da realização do datum conceitualmente preendido $^{7}$.

Whitehead de cara descreve a apetição como "matéria imediata de fato", ("immediate matter of fact") que inclui em si mesma um princípio de inquietude, ou seja, um princípio que envolve a realização do que não é e pode ser (1985, p.31). Na apetição, uma condição imediata condiciona a criatividade de modo a buscar a realização física de um polo mental. Esse polo mental, por sua vez, organiza valorizações inerentes à suas preensões conceituais.

Uma leitura apressada dessa frase poderia nos levar a pensar nas apetições como características exclusivas de seres vivos, ou mesmo talvez de organismos complexos. O que poderia ser reforçado pelos dois primeiros exemplos que ele dá, das apetições da sede e da auto-preservação. Mas precisamos explicitar melhor o que quer dizer em Whitehead uma preensão conceitual para entender que este não é

\footnotetext{
${ }^{6}$ Leibniz também diz, ainda na monadologia, que almas agem de acordo com as leis das causas finais, por apetições, fins e meios. Já os corpos se movem pelas leis das causas eficientes, e os dois domínios estariam em harmonia.

${ }^{7}$ No original: Appetition is at once the conceptual valuation of an physical feeling combined with the urge towards realization of the datum conceptually prehended (WHITEHEAD, 1985, p.33)
} 
o caso. Não estamos falando só de desejo no sentido mais trivial, de imagens e pulsões no teatrinho corporal subjetivo de alguém, mas tampouco estamos lidando exatamente com as máquinas desejantes de Deleuze \& Guattari, até onde entendo, com sua generalização surrealista do desejo como voragem maquínica. As apetições de Whitehead estão ligadas a uma bacia ainda mais vasta de interação, um espectro de potência relacional que no final das contas se reporta à criatividade primordial de Deus. Mas vamos com calma.

O polo mental da sede não sente só uma carência ou um desconforto vago, ele tem pra si o conceito daquilo que precisa para satisfazer essa apetição por meio do polo físico. Água.

Mas como podemos entender essa divisão entre o polo mental e o físico, que a princípio podem parecer uma re-edição infeliz de um dualismo Cartesiano?

Whitehead explica no final do livro que em cada atualidade "há dois polos concrescentes de realização - 'gozo' e ‘apetição', isto é o 'físico' e o 'conceitual’” (WHITEHEAD, 1985, p.348). Um polo físico é "por sua natureza exclusivo, atado pela contradição", enquanto um polo conceitual "por sua própria natureza abraça tudo, desatado de contradição" (WHITEHEAD, 1985, p.348). Por sua vez, o polo fisico deriva sua porção de infinitude da infinitude da apetição, enquanto o polo conceitual deriva sua porção de limitação do caráter exclusivo da fruição. A apetição conceitual é infinita e desatada enquanto a satisfação física é exclusiva e atada.

A conceitualidade funcionaria como uma potência relacional extensa ilimitada, enquanto a fisicalidade seria a própria limitação subjetiva da contradição ${ }^{8}$. Talvez estejamos nos adiantando, é bom recuar um tantinho. Para entender como se opera essa atualização concreta da conceitualidade, acho que precisamos compreender melhor o que é uma preensão.

Talvez a maneira mais simples de começar a compreender uma preensão seja como uma apreensão não-cognitiva. Na nossa escala, não seria tão diferente das pequenas percepções de Leibniz. As preensões em Whitehead se dividem em positivas e negativas. Uma preensão positiva, no vocabulário de Whitehead, se traduz por sentimento. Um sujeito (o que não equivale dizer um ser humano) seleciona objetos eternos para ingressar na sua constituição formal, isto é, determina os itens de satisfação de um sentimento. Mas os objetos eternos que não são selecionados não são por isso, totalmente negligenciáveis, porque além da preensão positiva resta a ligação de uma preensão negativa, que também tem sua própria forma subjetiva, ainda que fraca. Essa ligação negativa com todos os potenciais que não estão atualizados naquele evento adiciona algo ao complexo emocional, ainda que

\footnotetext{
${ }^{8}$ No original: A physical pole is in its own nature exclusive, bound by contradiction: a conceptual pole is in its own nature all-embracing, unbounded by contradiction. The former derives its share of infinity from the infinity of appetition; the latter derives it share of limitation from the exclusiveness of 'enjoyment'.
} 
não para as informações objetivas ${ }^{9}$. É assim que se pode dizer que qualquer criação envolve todo o universo (como preensão positiva ou negativa, selecionando ou excluindo todos os demais eventos do universo).

Preensões são espécies de vetores, transmissões de modos de energia potencial para seus modos determinados de atualização estruturada. São uma das grandes invenções conceituais de Whitehead. Se as entidades atuais são as coisas reais derradeiras das quais o universo é feito, cada entidade atual se reproduz em uma preensão. Uma preensão, no entanto, é subordinada à entidade atual, que por sua vez tem uma medida de relativa liberdade criativa (já que toda entidade atual para Whitehead é causa sui, como a substância Spinozista, ainda que condicionada pelas rotas do passado). A preensão pode ser compreendida como potência relacional concreta da criatividade ao mesmo tempo auto-determinada e condicionada de uma entidade atual.

$\mathrm{Na}$ sua apresentação das 'preensões' Whitehead diz que as mônadas de Leibniz devem ser compreendidas como generalizações do conceito atual de mentalidade. É por aí que vemos que Whitehead não reitera aqui o dualismo de Descartes com essa divisão entre polo mental e físico. Para a filosofia do organismo, preensões conceituais estão presentes nas coisas, não só no sujeito moderno que as pensa. A mentalidade está presente na Res Vera, não só na Res Cogitans. Preensões conceituais, na forma de vetores de tranmissão informacional concreta e de satisfação subjetiva formal, estão por trás do dinamismo relacional das entidades atuais, que envolvem a si mesmas pelas preensões que fazem umas das outras ${ }^{10}$.

Essa generalização da mentalidade e da energia como sentimento nos leva a contextualizar melhor a apresentação do conceito de apetição em "Processo a realidade". Ela se dá no capítulo III, “Algumas noções derivativas", que sucede a apresentação do seu robusto e idiossincrático "Esquema Categórico". Whitehead começa fazendo referência a algo que ele chama de natureza primordial de Deus (1985, p.31), que estaria ligado a uma avaliação conceitual incondicionada da multiplicidade inteira dos objetos eternos.

Se não fosse Deus, ele diz, os objetos eternos que não estão realizados no mundo atual seriam relativamente não existentes (itálicos meus) para a concrescência em questão. Whitehead enxerga então a necessidade de um ordenamento divino no mundo, mas diz que esse ordenamento seria uma "matéria

\footnotetext{
${ }^{9}$ No original: For each negative prehension has its own subjective form, however trivial and faint. It adds to the emotional complex, though not to the objective data.

${ }^{10}$ Essa visão das entidades atuais preendendo umas as outras não parece de todo dessemelhante da compreensão monadológica atualizada de Gabriel Tarde, para quem toda coisa era ávida e a sociedade era a possessão recíproca de cada um por todos (2012, p.123). Por mais que Tarde e Whitehead sejam extremamente díspares no método e no estilo, ambos autores partilhavam da compreensão de conjuntos de seres vivos, células e átomos como espécies de sociedades.
} 
imediata de fato" ("immediate matter of fact) que condiciona a criatividade. E diante disso, extrai a curiosa conclusão de que uma "possibilidade que transcende matéria temporal realizada de fato tem uma relevância real para o avanço criativo" (1985, p.31).

Whitehead parece, a princípio, estar aqui recorrendo ao salto conceitual mais tradicional do mundo, um Deus que organize tudo e coloque cada objeto eterno na sua raia de ingresso na hora certa. Mas ele o faz não para explicar um universo estático, mas para explicar como algo não-ainda-criado pode vir a adquirir relevância em um mundo de coisas já criadas.

Em seguida, no texto, Whitehead explica melhor o seu conceito de criatividade, do qual trataremos melhor no próximo item. Antes de falar da criatividade, precisamos encarar este conceito whiteheadiano de Deus, que talvez seja mais estranho que o de Spinoza. Apesar de alguns de seus atuais leitores tentarem evitar o teísmo no seu sistema, principalmente os muitos que chegam a Whitehead via Deleuze, eu não acredito que essa estratégia seja sempre recomendável e tampouco no geral muito viável. Não tanto porque significa uma distorção da sua obra (distorções podem ser extremamente proveitosas), mas porque perdemos com isso um dos elementos mais estranhos do seu sistema, e dos mais arredios à sensibilidade crítica contemporânea. No mínimo, precisamos tentar entender melhor o que faz a divindade de Whitehead antes de descartá-la.

Pelo menos nesse momento do livro, o Deus de Whitehead funciona como uma espécie de repositório de toda a multiplicidade de potenciais não-atualizados. Deus seria o fato de que há no mundo mais formas em potencial do que formas atualizadas. Ele aparece para explicar a geração de novidade e diferença, não para iterar a sua própria semelhança. Ele é, ao mesmo tempo, princípio de concreção e o impulso eterno do desejo. Ele salva o mundo (da maneira que salvamos um arquivo), mas não o cria (ou não mais do que ele é criado pelo mundo)

Não é possível apresentar uma descrição exaustiva aqui, mas basta dizer que Whitehead apresenta Deus como oposto contrastado do Mundo na tarefa da criação, Deus é imanente no mundo da mesma forma que o mundo é imanente em Deus ${ }^{11}$, num vislumbramento em que um serve de figura e o outro de fundo, e vice-versa, com a relação a todo tempo contrastada de novo. Apesar de Whitehead manter muito do vocabulário tradicional e mesmo do sentimento religioso do senso comum ocidental para compor a sua figura de Deus, em momentos parece ser um caso curioso de uma divindade monoteísta que se constrói de baixo pra cima, por se assim dizer. Constrangido na sua atualização,

\footnotetext{
${ }^{11}$ Essa é a quarta de seis antíteses que Whitehead apresenta em grupo no último capítulo do livro. Em cada uma delas há uma mudança de sentido que converte a oposição em contraste. É quase uma versão em koans da dialética, onde polaridades não se resolvem em uma síntese destruidora e preservadora mas sim mantém sua polaridade tensionada em um contraste expressivo.
} 
ainda que não na sua potência, pela contingência criativa e coletiva da concretude delimitada de suas decisões passadas.

Talvez não seja injusto dizer do Deus de Whitehead, em relação ao teísmo trivial, o mesmo que Whitehead diz do sujeito na sua filosofia em relação a de Kant. Para o teísmo trivial o mundo emerge de Deus, enquanto para Whitehead Deus emerge do mundo. Parece guardar alguma semelhança com o Deus que é gestado junto com o tempo na obra nunca-terminada de Schelling, "As Eras do Mundo" (Weltalter).

De qualquer forma, Whitehead deixa bem claro que o conceito de apetição precisa ser compreendido em relação ao caráter primordial de Deus. Deus contempla a multiplicidade dos potenciais, mas estes apenas se encontram atualizados nas entidades atuais. Essa ideia de "apetição", então, envolve não só o caráter de uma satisfação subjetiva circunscrita, mas toda a vasta propensão coletiva cósmica que condiciona a criatividade de qualquer evento, a trama física e conceitual de toda a potência relacional que pede para acontecer, toda a vasta extensão polirítmica que está latente e esperando por concreção debaixo de qualquer cadência estereotípica.

Se em qualquer sede ou voragem podemos encontrar um esforço coletivo do universo em busca de uma determinada satisfação subjetiva, nós também podemos remontar qualquer tensão energética ou tendência estrutural a um nexo extenso de mentalidade potencial em processo.

Não é só o potencial que está ali, evidente, claro, pendendo da atualidade como uma manga de uma mangueira, mas o espectro mais vasto de interação e de variedade dinâmica possível e imprevista, todo o espaço de fase expressivo de um campo de disparidade em tensão. Não é a ideia de que, digamos, a forma ideal de uma ninfa está em potência dentro de um bloco de mármore. Mas a eventualidade rítmica concreta daquele pedaço de mármore, que se revela ao longo da sua destruição controlada, com seus veios e suas linhas; na interface entre mão, instrumento e pedra, além da comodulação do protótipo figurativo tradicional coletivo da ninfa com a sensibilidade do escultor. Todas essas apetições se encontram aninhadas ${ }^{12}$ nessa trama relacional comportando suas próprias dimensões de satisfação subjetiva (compostas de durações de diferentíssimas espessuras).

12 Tomo emprestado o termo ("nested") da antropologia da arte de Alfred Gell (1998), que oferece soluções muito interessantes para se tentar pensar a dimensão artística fora dos limites da sua concepção moderna e Ocidental. Resumindo bastante, Gell pensa na arte e na produção de objetos artísticos na forma de distribuição e modulação de agência social. Além de um vocabulário rigoroso e robusto para tentar dar conta das inúmeras diferentes formas de ação que podemos projetar nas tramas coletivas que produzimos, Gel produz diagramas que tentam demonstrar a mistura de agentes materiais envolvidos, por exemplo, tanto em um quadro notável de Goya quanto no ato de retalhar esse quadro como protesto feminista. O que estou tentando fazer com a ideia de "apetição" aqui tem muito a ver com a expansão modulada que Gell faz do termo "agência". 
Uma pele de tambor, ou um prato, percutidos estão sofrendo uma série de deformações nas sua superfícies que não vemos, ou mal vemos, mas que estão por trás da variedade sonora que o sample de uma caixa nunca terá, ainda que tente simular as irregularidades estocáticas do real. Quando a produção de um filme captura luz de um determinado lugar para produzir uma cena, as apetições atadas naquela trama artística incluem não só os diagramas de desejo aninhados e montados numa sucessão rítmica narrativa, não só a soma de decisões conscientes que selecionaram informação, organizaram a sua produção e sua montagem derradeira, mas também a soma de contingências materiais que se capturam no processo, toda a eventualidade processual dos grãos ou bits de luz e som capturados nas condições singulares que foram capturadas, e que mesmo moduladas, editadas e filtradas ainda traem, sempre, as infidelidades contingentes do meio e a opacidade irredutível da matéria.

Whitehead também chama a apetição do "sentimento de relevância determinada para um mundo prestes a ser" $\left(1985\right.$, p.163) ${ }^{13}$. Apetições descrevem, portanto, todas as tendências e tensões presentes e pregnantes em um campo problemático e guardando potencial para estruturação ou amplificação em outros meios.

$\mathrm{Na}$ publicidade, por eemplo, figuras de desejo e de medo são diagramadas em tramas de satisfação e frustração de apetições materiais. Nexos da imaginação coletiva são atados em feixes de estímulo atomizado disponível para concreção de apetições corporais. A apetição oral se vê canalizada não só como vontade de fumar, mas como vontade de fumar esse objeto que sai desse pacote

\section{A criatividade apetitiva como princípio processual derradeiro: da matéria ao ritmo}

No mesmo capítulo onde Whitehead apresenta as apetições, ele antes disso apresenta assim o seu conceito de criatividade:

Criatividade é uma outra versão da 'matéria' Aristotélica, e da 'coisa neutra' moderna. Mas é despida da noção de receptividade passiva, seja de forma, seja de relações externas; é a pura noção de atividade condicionada pela imortalidade objetiva do mundo atual (WHITEHEAD, 1985, p.31).

${ }^{13}$ No original: The feeling of determinate relevance to a world about to be 
Criatividade, então, é uma versão ativa da matéria, uma versão relacional e dinâmica. A crítica à passividade da matéria aristotélica também foi feita de maneira aguda no século passado pelo filósofo francês Gilbert Simondon (2013), que associa o hilemorfismo aristotélico à cadeia de produção escravista ${ }^{14}$, e hoje é recuperada por uma série de autores associados a um novo materialismo (como Karen Barad, Manuel Delanda e Isabelle Stengers).

De fato, a ênfase que Whitehead dá para a criatividade pode ser vista como uma prefiguração de desdobramentos científicos mais recentes em torno das ideias de complexidade, emergência e autoorganização (STENGERS, 2014, p. 43). Para Didier Debaise, a criatividade é o conceito central que organiza o método especulativo de "Processo e Realidade". O grande tomo de Whitehead tem como orientação principal conseguir explicar tanto a extensividade cósmica quanto a produção contínua de novidade, e para tanto essa noção de criatividade é colocada como a noção derradeira de sua filosofia. Uma criatividade que é, no seu todo expansivo, a produção de uma conjunção a partir da disjunção, e que é diferente de suas atualizações mas só existe nelas (DEBAISE, 2009, p.37).

Ou, nas palavras maravilhosas do próprio Whitehead: “A criatividade é o derradeiro por trás de toda as formas, inexplicável por formas, e condicionado por suas criaturas.” (1985, p.21)

Em outro momento, Whitehead tenta explicar os limites do conceito tradicional de matéria como sendo essa coisa contínua de atributos persistentes, como diríamos da aparência e da sensação de uma pedra. A teoria molecular primeiro rouba a pedra de sua aparente quietude e passividade, e depois disso, as compreensões modernas do átomo passam a vê-lo como "sociedades envolvendo ritmos" (Whitehead, 1985, p.78). E só para terminar com o que poderia restar da imagem reconfortante de autoidentidade material persistente e contínua, os quanta fazem sua misteriosa aparição, parecendo se dissolver em vibrações de luz (Whitehead, 1985, p.79), assim como faz o material das estrelas. Quer dizer, a solidez da matéria devém da vibração, os elementos fundamentais de construção de pedras não são tijolinhos minúsculos, mas um campo de forças ritmadas que é parte de uma coreografia energética maior $^{15}$.

\footnotetext{
${ }^{14}$ Há ainda o fato de Aristóteles associar a forma com o masculino e a matéria com o feminino, como já foi apontado por Luce Irigaray (1984). Pode-se dizer que o hilemorfismo configurou conceitualmente, portanto, o domínio técnico da Pater Forma sobre a Mater Materia.

${ }^{15}$ Portanto (e aqui já não estou falando de Whitehead), alguém que se pretenda hoje em dia um materialista no sentido em que Lucrécio, Diderot ou Marx foram materialistas, deveria atentar para a sobreposição de ritmos técnicos humanos com os ritmos naturais do nosso meio e da nossa constituição fisiológica.
} 
Digo isso tudo para apontar que, se Whitehead substitui a matéria passiva aristotélica pelo criatividade, e se ele critica o conceito de materialismo por não dar conta do caráter rítmico da matéria, tudo leva a crer que a criatividade seria, por sua vez, um evento rítmico.

O próprio Whitehead chega a dizer, de maneira mais lateral do que sistemática, que o processo criativo é rítmico (sem dar a essa frase um papel deliberado no seu edifício conceitual). O que efetivamente se afigura com eminência na trama conceitual de Whitehead são as noções de emoção e sentimento (nas formas conceituais, mais especificamente, de energia e preensão positiva).

Não estou dizendo que Whitehead ofereça uma ontologia rítmica explícita, mas sim que a sua generalização metafísica da emoção e do sentimento como subjetividade formal distribuída pelo cosmos parece coerente com uma ontologia orientada a ritmos, como proposta (2016) por Hilan Bensusan (ou, ainda, como esboçada de maneira ousada por Spinoza na chamada "Pequena Física" de sua Ética). Uma intensidade emocional quantitativa é um vetor, mas sua eventualidade relacional se dá numa trama de durações sobrepostas, e a pluralidade subjetiva ampla e irrestrita de que Whitehead trata é uma trama cosmopolítica polirítmica.

Compreender o caráter rítmico da eventualidade concreta do mundo em todas as suas escalas (dos átomos até a nossa experiência em primeira pessoa) me parece tornar mais inteligível a proposta Whiteheadiana de generalizar a experiência e a subjetividade para toda entidade atual. Nesse sentido, a ritmicidade de um processo seria, justamente, a sua dimensão formal de satisfação subjetiva. A compreensão de que tudo sente poderia, então, ser compreendida materialmente na forma de tudo ressoa.

Podemos pensar na apetição, então - já transplantando o conceito para o nosso campo problemático da arte - como tensão ou tendência rítmica transdutiva de uma matéria expressiva. Sem dispensar inteiramente a referência de Whitehead a toda essa dimensão divina primordial, mas tentando transpô-la, até onde for possível, a termos informacionais imanentes, faço referência à filosofia ontogenética de Gilbert Simondon, e em especial o seu conceito de transdução como transferência de um meio energético para outro que se dá como estruturação recursiva (com a camada já formada servindo de base para a camada em via de se formar).

A apetição então, seria uma tensão informacional ou tendência formal que aguarda um disparo para se concretizar, uma fonte de energia ou uma montagem pregnante para se propagar ou se amplificar através de um meio, maneira singular de um material fluir e co-modular seu domínio rítmico de estruturação energética, transduzindo apetições de um meio para outro, seja este domínio um conceito, uma canção, um circuito imagético ou um pedaço de papelão. 
A produção de uma composição artística pode ser descrita como a transdução de apetições físicas de um meio em um gesto material iterável ou reverberável segundo os termos das apetições conceituais de alguma trama imagética coletiva.

A trama de qualquer composição artística, mesmo a mais simples, é um nexo espaço-temporal que retém e protensiona apetições materiais heterogêneas de uma dada ecologia de meios. Tramas nos envolvem em sua concreção relacional e desdobram potências afetivas do nosso corpo a partir do desdobramento rítmico da configuração de suas apetições materiais. Toda coisa tem seu próprio vórtice, como diria William Blake. Uma das maneiras de entender isso é que toda coisa implica uma perspectiva, outra é dizer que toda trama artística configura uma apetição material, diagrama por meio da configuração material de um corpo o movimento coordenado de outro.

As apetições poderiam ser pensadas como potências relacionais transdutoras, tanto dos esquemas e diagramas virtualmente aninhados quanto dos fluxos já atualizados de matéria. Isso valeria para descrever, digamos, tanto a sobreposição de desejos de um corpo que se põe a criar ou repetir tramas artísticas quanto a disposição dos materiais ordenados na trama artística, tanto a potência expressiva de um pedaço de madeira quanto a potência relacional de um diagrama abstrato. Quando uma canção toca no rádio, a concreção da trama artística não envolve apenas a retenção e protensão de apetições corporais por meio da batida, da melodia e dos sentidos das palavras, mas ainda a materialidade sonora das ondas gravadas em sua modulação da onda portadora, por meio da condutividade do cosmo eletromagnético. A canção, ao tocar no rádio, envolve todas essas apetições díspares, por mais que nem todas elas se realcem como contrastes nas dimensões mais imediatas da sua interface expressiva. $\mathrm{O}$ fato de uma apetição não ser conscientemente percebida não quer dizer que ela não esteja presente de maneira atual e concreta no feixe da composição.

Além de tudo que está materialmente atado em um feixe composicional, as apetições também envolvem toda uma extensão de preensões conceituais mais ampla de que uma interface expressiva precisa participar para poder se concretizar. Todo samba minimanente sincopado (ou seja, todo samba), além de suas qualidades líricas e musicais singulares, está participando também da sobreposição contrastada do dois, do três e do quatro. O fato de que não precisamos contar quando dançamos não quer dizer que não estamos maquinando e medindo quantidades e proporções quando nos deixamos arrastar por uma batida.

Um diagrama relacional artístico projeta um mundo ao mesmo tempo que se constrói por meio do constrangimento criativo contingente da sua matéria expressiva. Tomar a criatividade de Whitehead 
como processo rítmico pode ser um caminho para compreender ou explicitar tanto a sua eventualidade concreta quanto a sua subjetividade formal.

\section{Conclusão: Ecologias de meios e feixes de apetições}

Até agora, acho que deixei mais pontas soltas do que amarradas. Infelizmente, meu conhecimento limitado da obra de Whitehead não me permite fazer um apanhado mais substancioso da sua potência para o campo da filosofia da arte. O que foi esboçado aqui, então, é apenas uma versão parcial do que se pode fazer com Whitehead nessa direção, a partir de uma leitura expansiva do conceito de "apetição".

É difícil transplantar os termos de Whitehead sem trazer consigo o seu teísmo e o seu idealismo (mesmo que seja um teísmo transitivo e um idealismo energético ou sentimental). Claro que é possível tentar fazer leituras totalmente materialistas de Whitehead, mas acho que isso não deve vir com o custo de perder elementos importantes do seu sistema.

Como William James, Whitehead tentava dar conta da complexidade do mundo a partir de uma compreensão pluralista do universo fundada na variedade de espessuras da experiência. Uma ecologia dos meios materiais tenta tomar a produção de arte em sua dimensão relacional extensa e polifásica, não só pela dependência energética que toda atividade humana tem da ecologia geral do sistema Terra, mas pela participação que qualquer estrutura formal toma de um espectro vasto de mentalidade processual.

O mundo está todo prenhe de apetições de diversas ordens, em todas as escalas. Cabe aos artistas encontrarem na sua trama relacional concreta os feixes, os encaixes e as montagens que permitam reunir, sistematizar, co-modular e amplificar as tensões que os cercam.

O ritmo nos arrasta através de todas as escalas e a criatividade é um evento rítmico que nos antecede. Antes do gozo de qualquer satisfação física há o ímpeto conceitual que a invoca no mundo. O tempo é o avanço criativo no novo e uma invenção artística ousada ata apetições pregnantes em um protótipo transfigurador. Há muito mais potencial pregnante por aí entre as preensões conceituais do mundo do que diriam as nossas vãs atualidades institucionalizadas. O vocabulário de Whitehead nos propicia a encarar os mundos que se podem parir de tudo que ainda não é.

\section{Referências Bibliográficas:}


BENSUSAN, Hilan. Being up for Grabs. London: Open Humanities Press, 2016.

DEBAISE, Didier. Un Empirisme Spéculatif. Librairie Philosophique Jacques Vrin, Paris, 2006.

GELL, Alfred. Art and Agency. Oxford: Oxford University Press, 1998.

LEIBNIZ, Gottfried. A Monadologia e outros textos. Editora Hedra, Rio de Janeiro, 2008.

SHAVIRO, Steven. No Criteria. MIT Press, Boston, 2009

SIMONDON, GILBERT. L'Individuation à la lumière des notions de forme et de information. Paris:

MILLON, 2013.

STENGERS, Isabelle. A constructivist reading of Process and Reality. In: The Lure of Whitehead ( Nicholas Gaskill and A. J. Nocek, ed.). University of Minnesotta Press, Minneapolis, 2014.

TARDE, Gabriel, Monadologia e Sociologia. Cosac Naify, São Paulo. 2012

WHITEHEAD, Alfred North. Process and Reality, The Free Press, New York, 1985 . Adventures of Ideas, The Free Press, New York, 1967

Recebido em: 30/06/2019

Aprovado em: 27/10/2019

* Esse trabalho é licenciado pela Creative Commons Attribution-NonCommercial 4.0 International License 